\title{
ARE THERE REALLY SHORTCUTS? ESTIMATING SEAT BELT USE WITH SELF-REPORT MEASURES
}

\author{
Fredrick M. StrefF and Alexander C. WagenaAr \\ The University of Michigan, Transportation Research Institute, Ann Arbor, MI 48109-2150, \\ U.S.A.
}

(Received 28 April 1988; in revised form 29 March 1989)

\begin{abstract}
We examined the utility of estimating rates of automobile seat belt use with selfreport measures. Self-report measures overestimate belt use rates compared to observational surveys of the same population. Laws mandating seat belt use did not substantially affect the degree to which self-reports are upwardly biased. We found self-report measures overestimate observed belt use by 8.9 to 19.4 percentage points or by a factor of 1.2 to 2 . Our best estimate is that self-reported seat belt use rates be discounted by 12 percentage points to estimate actual belt use rates.
\end{abstract}

\section{IN'TRODUCTION}

Measuring seat belt use with comprehensive observational methods is expensive. In contrast, telephone surveys can provide an efficient method for obtaining community, state, or nationwide seat belt use estimates. However, self-reports of belt use often do not accurately reflect actual behavior, especially in areas where belt use is mandated by law. A few studies have explicitly compared reported and observed belt use.

Waller and Barry (1969) were perhaps the first to compare reported and observed seat belt use. Reported belt use was gathered from questionnaires sent to car owners whose actual belt use was observed previously. Seventy-seven percent of drivers who reported they always use seat belts on short trips were observed using belts. Belt use observations made in urban areas were operationalized by Waller and Barry to represent belt use on short trips. Only $46 \%$ of drivers reporting they always use belts on long trips were observed using belts. Belt use observations made on the highway were operationalized as representing belt use on long trips.

Fhaner and Hane (1973) compared self-report and observed seat belt use in Sweden. Telephone interviews were conducted with drivers whose belt use was observed on repeated occasions prior to the interviews. Although self-reported belt use was highly correlated with observed belt use $(r=.73)$, belt use rates based on self-reports overestimated observed restraint use. Only $25 \%$ of those who reported they use their belts on every trip were actually observed using their belt on each occasion they were observed.

More recently, Stulginskas, Verreault, and Pless (1985) report comparisons of observed and self-reported belt use in Montreal, where a compulsory seat belt use law was in effect. Restraint use was recorded for all passengers of cars in which at least one of the passengers was a child who appeared to be under 11. A limited sample of parents whose telephone numbers were available from hospital records were interviewed the day the observation was made. Comparisons of observed and self-reported belt use rates for this population showed that parents overreported belt use both for themselves ( $24 \%$ reported use when none was observed) and their children (38\% of parents reported belt use by the child when none was observed).

Compulsory use laws might increase the extent to which respondents overreport belt use for several reasons. For example, the force of law may influence individuals to report they comply with the law, even though there are no legal sanctions tied to a verbal statement of seat belt nonuse. Subjects tend to provide socially desirable responses to present themselves in the best possible light (Carlsmith, Ellsworth, and Aronson, 1976). This social desirability bias might increase when belt use becomes compulsory. We 
therefore reviewed studies that provide data on differences between observed and selfreported belt use under compulsory vs. noncompulsory conditions.

Comparisons between self-reported and observed seat belt use have been reported recently in technical reports completed for the Arkansas Highway Safety Program (Parker, Patterson, and Phillips 1986), the Florida Department of Community Affairs (Potter, Blackman, Breeze, and Chang 1985), and the U.S. National Highway Traffic Safety Administration (data from New York State; Rood, Kraichy, and McCartt 1987). These reports cover states in which there was no compulsory seat belt use law in effect (Parker et al. 1986), a compulsory use law approved but was not yet in effect (Potter et al. 1985), and a compulsory use law in effect for four months (Rood et al. 1987).

Parker et al. (1986) found that $39.4 \%$ of 883 Arkansas adults selected using a multistage area random sampling technique and surveyed via telephone reported they used a seat belt the last time they were in a vehicle (see Table 1). In contrast, observational surveys showed that only $19.8 \%$ of Arkansas motor vehicle occupants were actually using seat belts. That is, seat belt use was overreported by 19.6 percentage points, a factor of two, in this state without compulsory use.

Potter et al. (1985) found that $26.6 \%$ of the 4,136 licensed drivers sampled in eight Florida metropolitan areas surveyed via random digit dialing reported they "always" wore their belts. Observational surveys in these eight areas found $22.3 \%$ of noninfant motor vehicle occupants using belts. Self-reported belt use estimates were 4.3 percentage points or a factor of 1.2 higher than observed belt use estimates. A compulsory belt use law had been approved in Florida at the time of the surveys, but had not yet taken effect.

In a study of the effects of New York State's compulsory use law, Rood et al. (1987) obtained self-report data from three random digit dialing surveys of 1,000 licensed drivers each survey. Observational data of more than 200,000 front-seat passengers each survey from a probability sample of 700 observation sites were also gathered at three points in time: (1) approximately four months after passage and two months before full enforcement of the belt use law (prelaw wave), (2) three months after full enforcement began (first postlaw wave), and (3) eight months after full enforcement of the belt use law began (second postlaw wave). During each of these three survey waves, self-reported belt use rates were higher than observed belt use rates. During the prelaw wave, observed belt use was $16 \%$, compared with a rate of $29 \%$ based on respondents who reported they "always" used seat belts. Self-reported belt use measured by the percentage of respondents who reported they always use belts overestimated observed use by 13 percentage points (a factor of 1.8) during their first survey wave (after passage of the law but before it went into full effect). During the first postlaw wave, observed belt use was $57.1 \%$, compared with a rate of $66.9 \%$ based on respondents who reported they always used seat belts. Self-reported belt use overestimated observed belt use by only 9.8 percentage points (a factor of 1.2 ). During the second postlaw wave, observed belt

Table 1. Observed vs. reported belt use

\begin{tabular}{|c|c|c|c|c|c|c|}
\hline Investigators & State & MUL Condition & $\begin{array}{l}\text { Observed } \\
\text { Belt Use }\end{array}$ & $\begin{array}{c}\text { Self-report } \\
\text { Belt Use }\end{array}$ & $\begin{array}{l}\text { Percentage point } \\
\text { Difference }\end{array}$ & $\begin{array}{l}\text { Overreporting } \\
\text { Factor }\end{array}$ \\
\hline $\begin{array}{c}\text { Parker ot al. } \\
1986\end{array}$ & Arkansas & $\begin{array}{l}\text { No MUL } \\
\text { Approved }\end{array}$ & $19.8 \%$ & $39.4 \%$ & 19.4 & 2 \\
\hline $\begin{array}{l}\text { Potter et al. } \\
1985\end{array}$ & Florida & $\begin{array}{l}\text { MUL approved } \\
\text { not in effect }\end{array}$ & $22.3 \%$ & $26.6 \%$ & 4.3 & 1.2 \\
\hline \multirow[t]{3}{*}{$\begin{array}{c}\text { Rood ot al. } \\
1987\end{array}$} & New York & $\begin{array}{c}\text { MUL approved } \\
\text { not in effect }\end{array}$ & $16.0 \%$ & $29.0 \%$ & 13 & 1.8 \\
\hline & & $\begin{array}{l}\text { MUL in effect } \\
\text { three months }\end{array}$ & $57.1 \%$ & $66.9 \%$ & 9.8 & 1.2 \\
\hline & & $\begin{array}{l}\text { MUL in effect } \\
\text { eight months }\end{array}$ & $46.0 \%$ & $62.5 \%$ & 16.5 & 1.4 \\
\hline $\begin{array}{c}\text { Streff and } \\
\text { Wagenaar } \\
1989\end{array}$ & Michigan & $\begin{array}{l}\text { MUL in effoct } \\
2.25 \text { years }\end{array}$ & $46.9 \%$ & $55.8 \%$ & 8.9 & 1.2 \\
\hline
\end{tabular}


use was $46 \%$, compared with a rate of $62.5 \%$ of respondents who reported they always used seat belts. Self-reported belt use overestimated observed belt use by 16.5 percentage points (a factor of 1.4).

Exploration of ways in which upwardly biased self-report belt use data might be used to estimate belt use rates is important for a number of reasons. An accurate method for converting inflated self-report estimates into figures that better represent actual belt use rates could be an efficient alternative to costly probability sample observational surveys. Many studies are conducted to assess relationships between self-reported attitudes, beliefs, and behaviors including belt use. Discovering the "true" nature of these relationships would be enhanced if inflated belt use rates could be adjusted. A comparison of observed and self-reported belt use may provide a better understanding of effects of data collection methods on belt use rate estimates. Different interview methods (e.g. telephone vs. roadside interviews), questionnaire items, wording, or response categories may affect accuracy of belt use rate estimates based on self-report.

This study had two main purposes. The first was to examine effects of interview methods on seat belt use estimates. To accomplish this we compared: (1) belt use estimates based on interviews conducted at the roadside with observed belt use of those same drivers who were interviewed, (2) belt use estimates from two different questionnaire items used in the roadside interviews, (3) belt use estimates based on a telephone survey with observational data collected during the same time period, and (4) the extent of self-report bias for telephone vs. roadside interviews.

The second purpose was to examine effects of compulsory seat belt use laws on belt use estimates based on self-reports and to provide preliminary estimates of the amount self-report estimates should be reduced to better estimate actual belt use rates. If implementation of compulsory belt use laws increases the social desirability of belt use, we would expect that the extent of belt use overreporting would be higher in jurisdictions where belt use laws had been implemented than those where such laws had been passed but not yet implemented, and that overreporting would be greater in jurisdictions that had passed a belt use law than in those where no such law had even been passed.

\section{METHODS}

\section{Direct observation and roadside interviews}

The goal of the observation and roadside interview sample design was selection of observation and interview sites that would accurately represent all motorists traveling on Michigan roads. To provide adequate coverage of the entire state, 240 intersections were selected using a multistage stratified probability sampling procedure. Results presented here were weighted to take into account differential selection probabilities in the sample design. Observation sites were limited to intersections with three-color cycling traffic signals to allow sufficient time for accurate observation of restraint use and to request the driver to participate in the interview. Observations were well distributed across hours of adequate daylight and days of the week.

Drivers observed at the 240 sites were asked to participate in a brief follow-up interview in exchange for a $\$ 5.00$ cash payment. Interviews were conducted near the intersections where observations occurred, generally in line-of-sight of the intersections where the motorist was initially approached.

The following items were observed prior to the interview: restraint use, estimated age, and sex of occupants of the six primary seating positions. The interview instrument contained two self-report measures of belt use. The first was, "Could you tell me how often you use your seat belt?" Response categories for this item were: Always, Most of the time, Sometimes, Seldom, and Never. Each of the response categories was read to respondents prior to their selecting a response. The second self-report use item positioned later in the interview followed items asking respondents to estimate for how long they had been using seat belts and what influenced them to start using belts. This second self-report use item read, "Out of your last 10 trips in a car, how many times did you use a seat belt when one was available?" The roadside interview and observation data 
collection was conducted in July 1987, two years after Michigan implemented a compulsory seat belt use law.

\section{Telephone survey}

Our objective was to survey a probability sample of adult (age 18 and over) residents of the State of Michigan. A dual-frame sampling method was employed to maximize response rates. In the dual-frame sample, a fraction of households with telephones were selected from a list of telephone households, and were sent a letter announcing that interviewers might call and ask them to complete a brief survey. All other subjects were selected using random digit dialing techniques. Compared to random digit dialing alone, dual-frame samples improve response rates from 8 to 13 percentage points (Traugott, Groves, and Lepkowski 1987). Within each household contacted, a listing of all adults was made, and the respondent to be interviewed was randomly selected. If the selected respondent was not available at the time of the first call, up to six callbacks were made to ensure an interview with the selected respondent. Telephone interviews and roadside observations were both conducted during October and November 1987, two years after Michigan implemented a compulsory belt use law.

\section{RESULTS}

\section{Response rates}

Of 4,487 total candidates selected into the roadside interview sample, $1,869(41.6 \%)$ completed roadside interviews. Response rates were examined by candidate seat belt use, gender, and age. There were no statistically significant differences between respondents and nonrespondents.

Completed telephone interviews were obtained from 752 respondents with an overall response rate of $68 \%$. Because data are not available for nonrespondents, respondents and nonrespondents cannot be directly compared; however, proportions of respondents for age, sex, income, and education categories are similar to statewide census distributions. Both observation surveys observed approximately 18,000 vehicle occupants, of which over 12,000 were drivers.

\section{Seat belt use estimates: Roadside interviews and observations}

Using point-biserial correlation, observed seat belt use was found to be positively correlated with self-reported frequency of belt use for the always-never scale $(r=.71$; $p<.001)$. However, even in face-to-face interviews self-reported belt use overreported actual belt use. Specifically, of respondents who reported "always" using belts, $94.0 \%$ were observed using belts at the time of the interview. Even though unbelted respondents knew the interviewer could observe that they were not using their belt, some still reported they always use their belt. Only $23.3 \%$ of respondents who reported using belts "most of the time" were observed using belts. Significantly, the proportion of respondents who reported always using belts $(42.5 \%)$ was almost identical to the proportion of respondents who were observed using belts (43.0\%). Figure 1 shows the proportion of respondents who were observed using belts and the proportions reporting each belt use level in the roadside interviews.

Observed belt use was also significantly correlated with self-reported number of times belts were used in the last 10 trips in a car $(r=.28 ; p<.001)$. The magnitude of this relationship is much smaller than that between observed belt use and the alwaysnever scale. Of respondents who reported using belts 10 times out of the last 10 trips, only $32.8 \%$ were observed using belts. Furthermore, only $28.2 \%$ of those reporting belt use 9 out of the last 10 trips were observed buckled, and only $13.1 \%$ of those reporting belt use 8 out of the last 10 trips were observed buckled. Asking people to recall their belt use on their last 10 trips is a poor method for estimating actual belt use. It would not be surprising if people were inaccurate in recalling belt use from the 9 trips prior to the current trip, but it is difficult to explain why only $32.8 \%$ of the respondents who reported they used their belts on all 10 of their last 10 trips were not observed using 


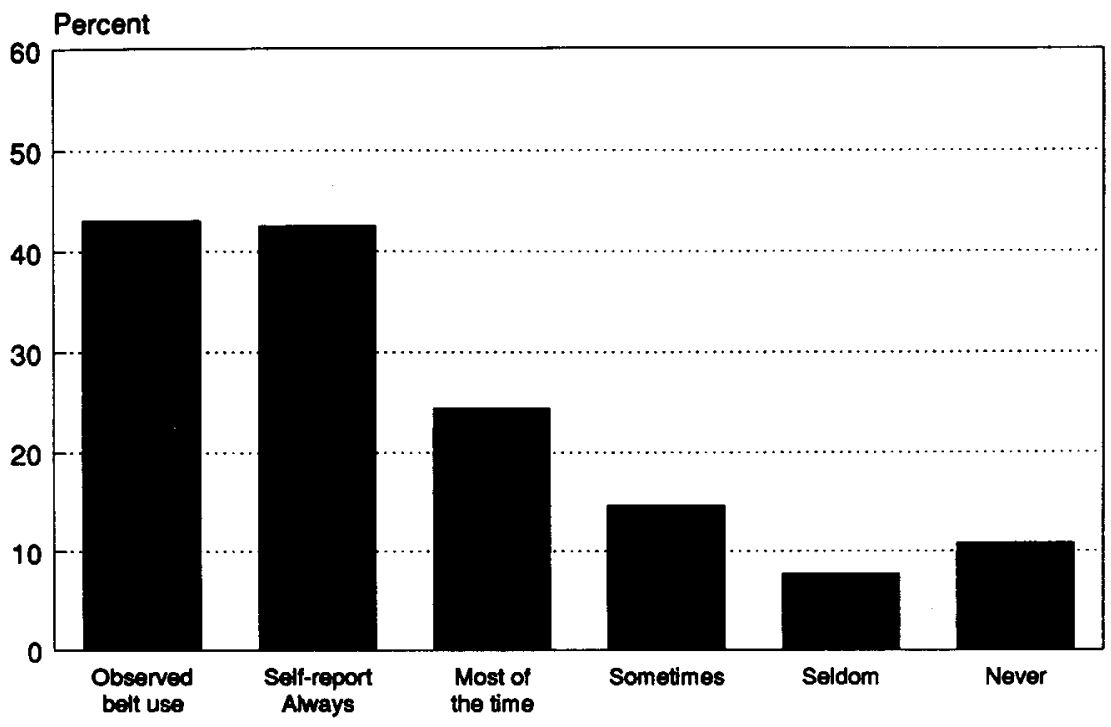

Fig. 1. Observed and self-report (roadside interview) belt use.

belts while $94 \%$ of those who reported they always use belts were observed wearing. Figure 2 shows the proportion of respondents using belts for each reported belt use level.

\section{Seat belt use estimates: Telephone interviews and roadside observations}

Nearly $47 \%$ of vehicle occupants observed in traffic were using a seat belt. The telephone survey found seat belt use to be higher. Among all respondents, 55.8\% reported they "always" used seat belts, $23.6 \%$ reported using belts "most of the time," $8.0 \%$ reported using belts "sometimes," $7.2 \%$ reported they "seldom" used belts, and $5.3 \%$ of the sample reported they "never" used belts. Note that unlike the roadside interviews, observed belt use was not accurately reflected by the percentage of respondents who reported they always use belts. Self-reported belt use based on the proportion of respondents who claimed they always used belts overestimated observed belt use by 8.9 percentage points or a factor of 1.2. Figure 3 shows the proportion of vehicle occupants who were observed using belts in the observation survey, and the proportions reporting each belt use level in the telephone interviews.

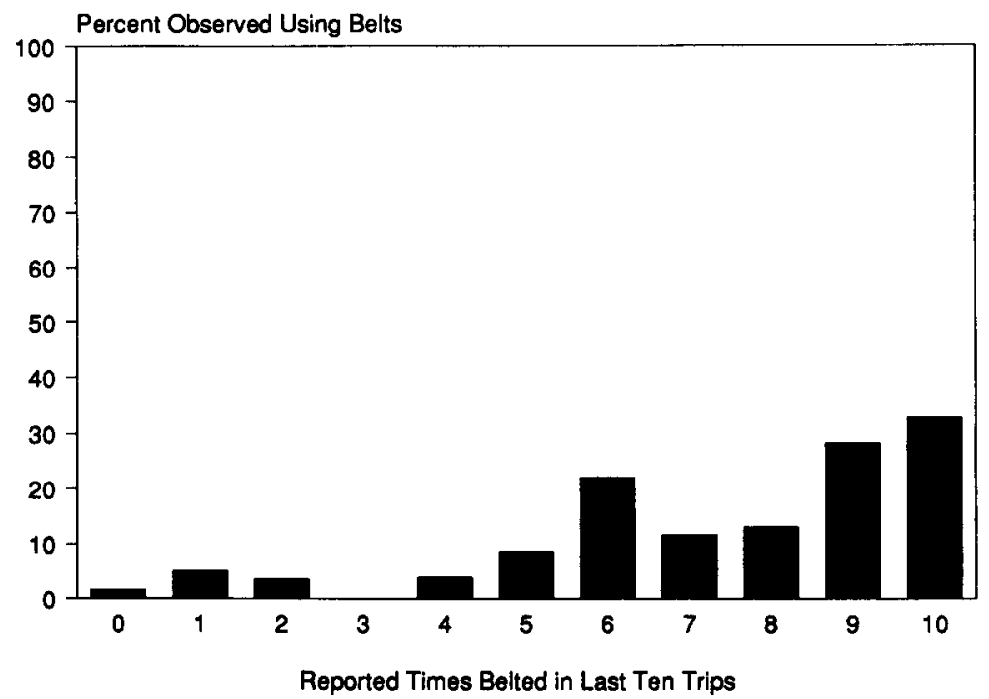

Fig. 2. Self-report belt use by observed belt use. 


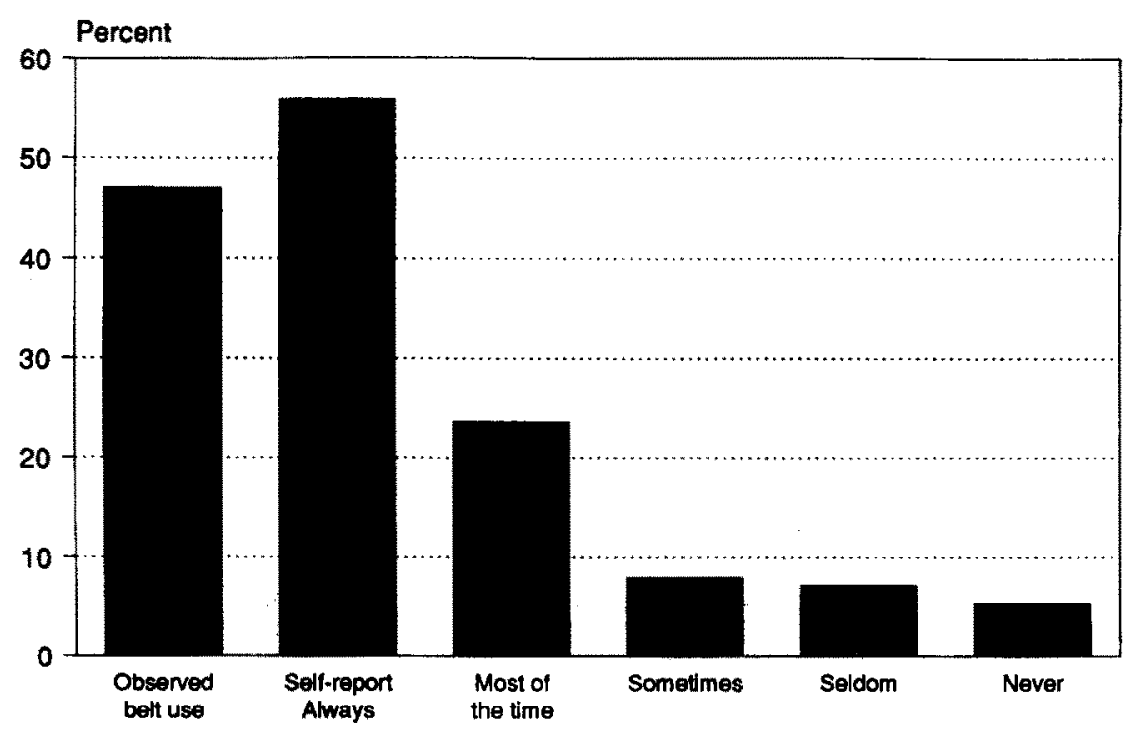

Fig. 3. Observed and self-report (telephone interview) belt use.

\section{DISCUSSION}

The interview method clearly had an impact on seat belt use estimates based on self-report. Belt use estimates based on roadside interviews were nearly identical to estimates based on observations of those interviewed if we consider only the proportion of respondents who reported they "always" use belts. However, always users based on telephone surveys considerably overestimated observed belt use. It is likely that individuals are less likely to exaggerate their belt use when they know their belt use has been observed directly. Support for this notion was shown in anecdotal reports from interviewers who reported many instances of roadside respondents saying things like, "I guess you caught me today, but I really do use my belt most of the time."

We also found that the item requesting an estimate of the number of times belts were used out of the last 10 trips item produced less accurate belt use estimates than the more general always-never scale. That is, there was a greater overreporting of belt use with the 10 trips item than with the always-never scale. Our results are in contrast to Hunter and Geissinger (1988), who argue that asking respondents to report belt use frequency over an extended or generalized period of time would produce higher use estimates than would be produced by use estimates based on a more finite period.

We hypothesized that belt use overreporting rates would be higher in jurisdictions where belt use laws had been implemented than those where such laws had been passed but not yet implemented, and that overreporting would be greater in jurisdictions that had passed a belt use law than in those where no such law had even been passed. Thus, discounting calculations would have to differ based on the progress of belt use laws in the jurisdiction in question. However, we found no consistency in overreporting rates based on the existence or age of compulsory use laws in the literature reviewed. Table 1 summarizes these findings. This lack of support for the hypothesized effect may be due to the simplicity of the hypothesis. There may be an interactive effect of social desirability and existence of belt use laws such that those persons most likely to report inflated belt use may be most effected by belt use laws. Some of this lack of consistency could be due to differences in methods used and samples obtained in each of the studies; however, the data from New York was collected using the same methods before and after implementation of the law, and the difference between self-report and observed data from New York did not confirm the hypothesized effect.

An alternative hypothesis to social desirability effects has been proposed to explain the difference between observed and self-report measures of belt use (Blatt 1988). This hypothesis suggests that observed differences are really due to sampling differences. 
Specifically, Blatt argues that roadside observations are likely to include younger drivers less likely to use belts and omit older drivers who are more likely to use belts (under compulsory belt use conditions) due to driving habits. Telephone surveys conducted in the daytime are more likely to contact older respondents who are reachable at home during daytime hours when some surveys are conducted. Thus, roadside surveys will underestimate belt use while telephone surveys overestimate belt use. This hypothesis was examined using our telephone interview and roadside observation survey.

In our telephone survey, $21.3 \%$ of the sample were age $18-30,53.4 \%$ were age $31-$ 59 , and $25.3 \%$ were age 60 and over. In the observational survey, $29.9 \%$ of the sample were age $16-29,57.8 \%$ were age $30-59$, and $12.3 \%$ were age 60 and over. These data support Blatt's contention that youth are undersampled in telephone surveys and oversampled in roadside surveys. Differences in age categories are due to differences in study designs. Observational studies were designed to measure belt use among groups affected by Michigan's belt law (those 16 and over). The telephone survey was of adults in Michigan (those 18 and over). However, these sampling differences do not fully explain differences in belt use between estimates based on self-report and observation. Differences between observed and self-reported belt use rates were found to differ by 10.9 percentage points (a factor of 1.3) for individuals in the youngest age group, 11.3 percentage points (a factor of 1.2) for individuals in the middle age group, and 8.1 percentage points (a factor of 1.1) for individuals in the oldest age group. Higher belt use estimates produced by telephone interviews compared to observations are not simply the result of sampling differences.

Finally, how might we best estimate actual belt use from biased self-report measures? As can be seen in Table 1, seat belt use rates based on self-report overestimates observed belt use rates by 8.9 to 19.4 percentage points, a factor of 1.2 to 2 . Generally higher overreporting factors were found in locations with low observed belt use. The difference in overreporting factors may be due in part to the small percentage of persons actually using belts in locations without laws in effect; thus, any overreporting is a larger proportion of the observed belt use rate. On the other hand, Florida had an observed belt use rate of $22.3 \%$, with self-reported belt use higher by only 4.3 percentage points, a factor of 1.2 .

It is difficult to determine precisely why the bias estimates examined differ so much. Perhaps a clearer pattern would emerge in overestimation bias if self-report and observation data were available from more locations. Because there are no consistent patterns to the differences in overreporting of belt use in the data described here, the best single estimate for discounting self-report estimates of belt use to approximate actial belt use may be the average of the available bias estimates. Thus, we suggest self-report belt use estimates be discounted about 12 percentage points to approximate actual belt use. What is clear is that self-reported seat belt use overestimates actual seat belt use, and selfreports should not be taken as an accurate measure of actual belt use.

Acknowledgements - The authors acknowledge the University of Michigan Institute for Social Research for conducting the telephone surveys. We also acknowledge the reviewers for their helpful suggestions. This research was supported by the Michigan Office of Highway Safety Planning and the National Highway Traffic Safety Administration; however, views expressed are solely those of the authors. Please send correspondence regarding this article to the first author at UMTRI, 2901 Baxter Rd., Ann Arbor, MI 48109-2150, U.S.A.

\section{REFERENCES}

Blatt, J. Surveys: Interpreting their results by examining their purpose and methods. Presentation at the 6 th Annual Lifesavers Conference; March 1988.

Carlsmith, J. M.; Ellsworth, P. C.; Aronson, E. Methods of research in social psychology. Reading, MA: Addison-Wesley; 1976.

Fhaner, G.; Hane, M. Seat belts: The importance of situational factors. Accid. Anal. Prev. 5:267-285, 1973.

Hunter, W. W.; Geissinger, S. B. Understanding and acceptance of the North Carolina Safety Belt Use Law. Chapel Hill, NC: UNC Highway Safety Research Center; February 1988.

Parker, T. V.; Patterson, J.; Phillips, T. A report on occupant restraint usage in Arkansas: Results of attitudinal and observational surveys. Little Rock, AR: Arkansas Highway Safety Program; August 1986

Potter, W. J.; Blackman, B.; Breeze, M. H.; Chang, I. C. Reported and observed seat belt usage levels of motor vehicle occupants in Florida. Tallahassee, FL: Florida State University Communication Research Center; March 1985. 
Rood, D. H.; Kraichy, P. P.; McCartt, A. T. Evaluation of New York State's mandatory occupant restraint law: Volume VI-final summary report. Report Number DOT HS-807-079. Washington, DC: National Highway Traffic Safety Administration; February 1987.

Stulginskas, J. V.; Verreault, R.; Pless, I. B. A comparison of observed and reported restraint use by children and adults. Accid. Anal. Prev. 17:381-386; 1985.

Traugott, M. W.; Groves, R. M.; Lepkowski, J. M. Using dual frame designs to reduce nonresponse in telephone surveys. Pub. Opin. Q. 51(4):522-539; 1987.

Waller, P. F.; Barry, P. Z. Seat belts: A comparison of observed and reported use. Chapel Hill, NC: UNC Highway Safety Research Center; May 1969. 